Safeguarding, its Genealogy and Governance.

Two Essays on UNESCO's

Convention for the Safeguarding of Intangible Cultural Heritage

\title{
The Governance of Safeguarding. Comments on Article 2.3 of UNESCO's Convention for the Safeguarding of Intangible Cultural Heritage
}

\section{Antonio Arantes ${ }^{1}$}

' Universidade Estadual de Campinas, Departamento de Antropologia, Campinas/SP, Brasil

\begin{abstract}
Reflexions on the key dispositifi adopted by Unesco's Convention on the Safeguarding of Intangible Cultural Heritage (Article 2.3). In these Comments, I initially situate the notion of 'safeguarding' in the context of transformations of other preservation instruments which it dialogues and to whose semantic field it belongs. Challenges to its implementation and possibilities opened by this treaty for the protection of what has been designated as 'folklore and traditional (and popular) culture'z are addressed. After offering an interpretation of its textual meaning in the Convention, I seek to explore how this device is articulated to others in this Convention, and to reflect on its possible practical reach.
\end{abstract}

Keywords: safeguarding; UNESCO ICH Convention (Art. 2.3); operational directives; folklore and traditional (popular) culture; intangible heritage management.

\footnotetext{
$1 \quad$ My understanding of Foucault's definition of 'dispositif' as applied to heritage theory and practice, as well as other conceptual issues raised in this essay, are discussed in Arantes 2019.

2 I use this formulation taking as a reference point the Recommendation on the Safeguarding of Traditional Culture and Folklore, adopted by the UNESCO General Conference on 15 November 1989, hereinafter the 1989 Recommendation, cited in the Preamble to the 2003 Convention.
} 


\section{A Gestão da Salvaguarda. \\ Comentários ao Artigo 2.3 da Convenção da UNESCO para a Salvaguarda do Patrimônio Cultural Intangível}

\section{Resumo}

Reflexões sobre o dispositivo-chave da Convenção da UNESCO para a Salvaguarda do Patrimônio Cultural Intangível (Artigo 2.3). Discutem-se desafios à sua implementação e questões práticas abordadas pelas Diretrizes Operacionais. Nestes Comentários, situo inicialmente a noção de 'salvaguarda' no contexto de transformações de outros instrumentos de preservação com os quais ela dialoga, e a cujo campo semântico ela pertence. Focalizo desafios à sua implementação e possibilidades abertas para a proteção do que tem sido designado 'folclore e cultura (popular) tradicional'. Após oferecer uma interpretação do seu significado no texto comentado, procuro explorar como este dispositivo se articula com outros previstos nesta Convenção, e refletir sobre seu possível alcance prático.

Palavras-chave: salvaguarda; Convenção da UNESCO para a Salvaguarda do Patrimônio Cultural Intangível (Art. 2,3); diretrizes operacionais; folclore e cultura (popular) tradicional; gestão do patrimônio intangível. 


\title{
The Governance of Safeguarding. Comments on Article 2.3 of UNESCO's Convention for the Safeguarding of Intangible Cultural Heritage
}

\author{
Antonio Arantes
}

\section{Subject and framing}

The 2003 Convention ${ }^{3}$ defines 'safeguarding' as follows:

"Safeguarding" means measures aimed at ensuring the viability of the intangible cultural heritage, including identification, documentation, research, preservation, protection, promotion, enhancement, transmission, particularly through formal and non-formal education, as well as the revitalization of the various aspects of such heritage.

This notion provides conceptual and practical parameters of central importance to the implementation of the 2003 Convention, since it concerns what Article 1 characterizes as the first of its purposes:

Purposes of the Convention. The purposes of this Convention are: (a) to safeguard the intangible heritage; (b) to ensure respect for the intangible cultural heritage of the communities, groups and individuals concerned; (c) to raise awareness at the local, national and international levels of the importance of the intangible cultural heritage and of ensuring mutual appreciation thereof; (d) to provide for international cooperation and assistance (emphasis added).

Safeguarding cannot be properly understood without taking in account its agents ${ }^{4}$ and the specificities of the objects to which it refers. ${ }^{5}$ It should also be considered that this regime is an instrument of a public policy that, by 'safeguarding' cultural practices, does not aim to conserve them as they occur in the real world but adds new constraints and possibilities that affect their original conditions of production and make them the object of new values and meanings. Consequently, these second-order cultural constructions, cultures on

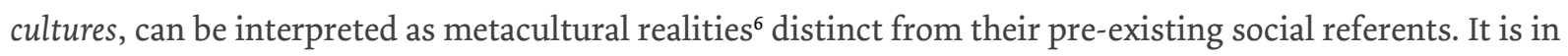
this new condition that they become part of the universe of Intangible Cultural Heritage (hereafter ICH) and establish reflexive relations with the social practices and ways of life on which they depend for their continuity.

\footnotetext{
3 Accronyms and abbreviations. 1972 Convention, Convention Concerning the Protection of the World Cultural and Natural Heritage. 1989 Recommendation, Recommendation on the Safeguarding of Traditional Culture and Folklore, 1989. 2003 Convention or the Convention, Convention for the Safeguarding of Intangible Cultural Heritage. CGIs, Communities, groups and individuals concerned. GA, General Assembly of the States Parties. IAR, International Assistance Requests.ICH, Intangible Cultural Heritage. IGC, Intergovernmental Committee for the Safeguarding of Intangible Cultural Heritage. Masterpieces Program, Proclamation of Masterpieces of the Oral and Intangible Heritage of Humanity. NGO, Non-Governmental Organization. OC, Organs of the Convention. OD, Operational Directives. RGP, Register of Good Safeguarding Practices. RL, Representative List of the Intangible Cultural Heritage of Humanity. SP, States Parties. USL, List of Intangible Cultural Heritage in Need of Urgent Safeguarding.

4 Here I consider, under the terms of the Convention, the following agents: Organs of the Convention (OC), namely the General Assembly of the States Parties (GA) and the Intergovernmental Committee for the Safeguarding of the Intangible Heritage (IGC), States Parties (SP) that act through the intermediation of diplomatic representatives at UNESCO and their own preservation agencies, and Non-Governmental Organizations (NGOs).

$5 \quad$ Articles 2.1 and 2.2.

6 On the notion of metalanguage and object language, see Roman Jakobson (1963) and Barbara Kirschenblat-Gimblett (2004).
} 
As a consequence, it is essential to examine - albeit succinctly, given the space limits of these reflections - the ways in which safeguarding affects the social experience of cultural communities.

As conceived under the Convention, safeguarding actions are primarily aimed at the communities, groups and individuals (hereafter CGIs) who comprise the social agents in whose ways of life the safeguarded cultural elements, the so-called ICH, are embedded. Nevertheless, these should not be understood as passive targets of these actions, since the effectiveness of safeguarding depends on their active participation. The respect shown by the Convention for the agency of the CGIs should also be stressed, along with the fact that they enjoy the prerogative of self-representation (Article 2.1), i.e. of recognizing aspects of their own social practices "as part of their cultural heritage" which, as a consequence, become an object of safeguarding. ${ }^{7}$ Members of the general public at local, national and international levels are here understood as indirect targets of the Convention (Article 1.b).

Given the necessarily broad scope of these reflections, dictated by the complexity and amplitude of the subject matter under consideration, and taking into account the space limits of this publication, I refer the reader to the database available at www.unesco.culture.ich, where detailed ethnographic information can be found on the situations discussed here, along with a number of critical studies cited over the course of this exposition.

\section{Mutations to the notion of safeguarding ${ }^{8}$}

Strictly speaking, the notion of 'safeguarding,' in the sense that interests us here, does not exist prior to or outside of the 2003 Convention, which institutes it as a device of a sui generis heritage regime.

Certainly, instruments for promoting and documenting cultural expressions, especially those identified as traditional, have been formulated and implemented over the decades. Museums and collections were created in metropolitan centres, especially over the nineteenth century, in the formation of nation-states. ${ }^{9}$ However, there were no international norms to protect what became known as ICH until the turn of the twenty-first

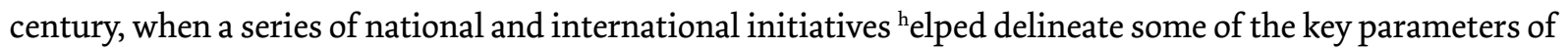
safeguarding, in an already globalized world.

David Harvey's (2001) reflections on heritage are worth recalling here since, according to him, this reality, contextualized by the changing relations between civil society and the state, is a process that participates in the political changes of its time, proving to be closely connected to the dynamic of citizenship. In this sense, the 2003 Convention inaugurates a conception of heritage and advocates forms of safeguarding appropriate to this sui generis object, adopting a paradigm of social participation and democratic access to culture rights which, though far from being universal, is both possible and viable in the present historical context.

In this process, political and conceptual possibilities for social engineering were envisaged and discarded, choices were legitimized and, no less importantly, networks were formed of actors and narrators of the trajectory that would lead to the realization of the 2003 Convention. ${ }^{10}$ According to diverse sources, ${ }^{11}$ the initial landmark in this process was the promulgation of the Recommendation on the Safeguarding of Traditional Culture

\footnotetext{
7 On this point, questions of free, prior and informed consent, as well as intellectual rights ask for careful consideration. See for instance Kono (2009). 8 Records of the various meetings that preceded the 2003 GA can be consulted at https:/|ich.unesco.org/en/working-towards-a-convention-oooo4, except for the International Meeting of Experts on Intangible Cultural Heritage "Establishment of a glossary" at UNESCO Headquarters in Paris, $10-12$ June 2002 reported by me and appended to the present Comments.

9 Examples: Peabody Museum of Archaeology and Ethnology (Harvard University, 1866); Musée de l'Homme (Paris, 1937); Pitt Rivers Museum (Oxford, 1884) and Museum of Archaeology and Anthropology (Cambridge, 1884); among others.

10 Among the numerous actors participating in this process, we can highlight Lourdes Arizpe (Assistant Director-General, Culture Sector, 1 July 1994 - 30 June 1998), Noriko Aikawa (former director of the ICH Section of UNESCO since its creation in 1992), and Koishiro Matsuura (appointed on November 12, 1999 to serve a six-year term as Director-General of UNESCO).

11 See for example Ikawa-Faure (2009).
} 
and Folklore ${ }^{12}$ (hereafter the 1989 Recommendation), cited in the Preamble to the Convention alongside the UNESCO Declaration on Cultural Diversity (2001) and the Istanbul Declaration (2003), as "a main spring of cultural diversity and a guarantee of sustainable development."

\section{Recommendation}

The effects of the 1989 Recommendation remain to be assessed, but they were probably limited in nature since this was not a legally binding instrument. However, it did set out parameters for the discussions and negotiations that led to the 2003 Convention. It will be useful to review this document, albeit quickly, in order to understand the textual meaning of 'safeguarding' adopted by the Convention. Additionally, it helps identify issues that reverberate around it and that, as commonly held views, are frequently expressed in the demands and arguments of various stakeholders, revealing an entire semantic field that gives it life and broader significance.

The object of the 1989 Recommendation is defined as folklore (traditional popular culture), understood as "the totality of tradition-based creations of a cultural community, expressed by a group or individuals and recognized as reflecting the expectations of a community in so far as they reflect their cultural and social identity." Setting out from the premise that these cultural legacies should be safeguarded by and for the group whose identity it expresses, this instrument provides a detailed description of the measures for identification, preservation, dissemination and protection. These measures would seek to mitigate the forgetting or complete loss of these tradition-based creations threatened by mass culture and to contribute to the revitalization of culture expressions at risk. Member States would be responsible for taking measures to strengthen research, the forming of collections and the archiving of records, to stimulate the dissemination of these traditions, and to protect the intellectual rights of those who are the transmitters of this legacy. Meanwhile its interpreters would have the mission of transmitting and revitalizing it.

\section{Proclamation of the Masterpieces of the Oral and Intangible Heritage of Humanity'3}

This Program (hereafter the Masterpieces Program) focuses on cultural elements of "outstanding value as a masterpiece of the creative genius of humanity" that present "excellence of skill and technical qualities" and are "threatened to disappear." ${ }^{14}$

This initiative was inspired by the 1989 Recommendation (which also highlighted the role of interpreters and transmitters, while emphasizing the cultural elements found to be at risk) and by the Convention Concerning the Protection of the World Cultural and Natural Heritage of 1972 (hereafter the 1972 Convention), like which it sought to raise the global profile of what it declared to be "unique testimonies" of the "creative genius of humanity."

As in the 1989 Recommendation, this Program privileged the production of knowledge on the selected cultural expressions, their documentation, transmission to the future interpreters and to the public in general, promotion, and the protection of intellectual rights. ${ }^{15}$ The proposed lines of action were: identification and inventorying; research and documentation; enhancing the transmission to younger generations; awareness raising; legal protective measures; and dissemination through specialized curricula in schools and universities. Differently to this Recommendation, the Masterpieces Program did not really address questions relating to

\footnotetext{
12 Adopted by UNESCO General Conference in Paris, 15 November 1989.

Created by Decision 23 adopted by UNESCO's General Conference at its $29^{\text {th }}$ Session, 1997 , and Regulated by Decision $155 \mathrm{EX} / 3.5 .5$, adopted by Executive Board at its $155^{\text {th }}$ Session, 1998. Proclamations took place in 2001, 2003 and 2005.

14 Wording adopted by 'Regulations relating to the proclamation by UNESCO of masterpieces of the oral and intangible heritage of humanity,' adopted by Executive Board's Decision 155 EX/3.5.5.

15 Although the instrument does not specify as such, it may refer to performance and image rights.
} 
the 'revitalization' of the Masterpieces at risk. The listed procedures can be interpreted as relatively 'noninvasive' from the viewpoint of their interference in the conception and performance of the safeguarded cultural elements, depending, of course, on the way in which these actions were executed.

The requirement of exceptionality - a prerequisite itself difficult to be identified and measured - proved to be inadequate, according to UNESCO's own assessment, since it presumed an undesirable hierarchy between cultural elements and potentially stimulated competition between social groups, if not nations. It thus contradicted the guiding principles of the ICH Convention which was then being elaborated as an instrument that aimed to "protect elements of the ICH that are relevant for the identity and continuity of groups and communities," encouraging peace and mutual understanding between peoples.

Arguably the main contributions of the Masterpieces Program were to raise awareness of the public and Member States concerning the symbolic potential of this heritage for the promotion of cultural diversity and the international visibility of countries and ethnic groups around the world. It is worth noting that Member States with fewer programs dedicated to natural or built heritage protection and promotion quickly applied as candidates to the Masterpieces Program, either through national requests, or through multinational proposals that enunciated the demands of ethnic groups whose traditional territories had been divided up by the colonial system. ${ }^{16}$

It is notable that, for practical purposes, the meanings of 'masterpiece,' 'exceptionality' and 'uniqueness,' despite being abolished from the language of the UNESCO/ICH regime, tend to be employed by States Parties, and indeed sometimes by local stakeholders, when referring to the presence of their cultural elements on the Representative List. This shift from, so to speak, the everyday to the 'exceptional' also suggests that the amplification of the symbolic effects undesired by the managers of the UNESCO/ICH regime along the lines stimulated by the Masterpieces Program is strongly echoed at a popular level. In terms of safeguarding, aestheticization as an important effect of the safeguarding of intangible heritage, even that practiced in accordance with the 2003 Convention.

\section{The path to the 2003 Convention}

The conceptions germinated over the 199 os became explicit and were debated at diverse meeting $\mathrm{s}^{17}$ promoted by UNESCO with the final objective of producing a draft version of the Convention. To illustrate the extent of these divergences - which in some ways are still present on the intellectual and ideological horizons of the innumerable actors involved in the implementation of this regime - I shall turn to comment on one of these meetings in which the aim was to establish a glossary capable of serving as a working tool for writing the draft of the Convention. I compare the records of the debates that took place on the theme of safeguarding - and the notion of ICH corresponding to it - in two documents, namely the text that served as a reference point for the meeting (hereafter Draft Glossary) ${ }^{18}$ and the text resulting from this meeting (hereafter Glossary) ${ }^{19}$ which was, soon after its elaboration, presented to the smaller group of draft writers approved by the GA and largely absorbed in the final version of the Convention. ${ }^{20}$

\footnotetext{
16 The Gule Wamkulu, Malawi, Mozambique, Zambia, 2015. Urtidin Duu (Traditional Folk Long Song), Mongolia, China, 2015. Shashmaqon Music, Uzbekistan, Tajikistan, 2003.

17 Chronology of the meetings according to the UNESCO site. Minutes of the meeting for preparation of the Glossary, Compare the text of the glossary and the text approved by the GA.

18 Draft glossary, Dutch experts convened by the bureau of the Netherlands National Commission for UNESCO (TER/CH/2002/WD/4).

19 Results of the International Meeting of Experts on Intangible Cultural Heritage 'Establishment of a Glossary,' in Paris, 10-12 June 2002, edited by this group between June and August 2002 (the Netherlands National Commission for UNESCO, doc. 00265/2002).

20 In these comments, I also refer to the minutes of the two meetings at which these documents were discussed, namely the $1^{\text {st }}$ and $2^{\text {nd }}$ Drafting Group Meetings Reports, of 12-13 and 13-15 June 2002 (respectively 'Report approved by Participants,' unnumbered, and Doc oo5152-En), hereafter Report1 and Report2.
} 
The conceptual shifts that occurred during the debates on the Draft Glossary towards its final version were described with precision in the minutes to this meeting, from which I cite the following:

the vast majority of experts consistently argued that one distinctive characteristic of this type of heritage is its intrinsically dynamic nature, due to the fact that it is an integral part of the social organisation and history of the communities concerned. It was also consensual that the future policies should not only take into account, but also actively recognise, the right and capacity that cultural communities have in making their own choices as to whether or not give continuity to aspects of their own culture. So, it became clear that the word that most adequately and broadly describes the particular kind of intervention that would be adequate to the nature of this heritage is safeguarding, and consequently that this should be chosen as the basic notion implied in this context. Consequently, the plenary endorsed the wording used by other commissions in the elaboration of the preliminary versions of the Convention. The types of action referred to in the definition of safeguarding (i.e. identification, documentation, promotion, revitalisation and transmission) are those that the experts felt adequate to this new policy and which are considered compatible with the definition produced by this meeting (Report 1, Agenda item 6).

This citation summarizes fundamental decisions concerning three important aspects of safeguarding according to the regime inaugurated by the 2003 Convention. One, perhaps the most fundamental, is the meaning of safeguarding actions, or in other words the reply to the question: what should they serve for? Intended in the Draft "to shield certain cultural practices and ideas," here they were designed "to ensure the viability" of the ICH. This is the finality to which the different planned measures would contribute.

In addition, considering that actions like conservation, preservation and protection, already well-established in preservationist practice, "may not be applicable to all aspects of intangible cultural heritage," the Glossary asserts: "for the purpose of the future convention, the adoption of the term 'safeguarding' is endorsed" and goes on to recommend that each of these actions should only be applied when appropriate.

The citation points to other important aspects of the UNESCO/ICH regime relating to social participation, to the recognition of the "creative ability of the people and of the constant transformation of heritage," and to the fact that "emphasis should be put on cultural processes, on the culture-bearing communities and in local agency, rather than in their products." ${ }^{21}$

In relation to the sensitive topic of revitalisation, instead of simply proposing that the agencies responsible for the heritage policies of the States Parties "reactivate or reinvent, or encourage people to reactivate or reinvent, cultural practices and ideas which are no longer in use, or are falling into disuse," as proposed by the Draft, the Glossary proposes that the subject should be approached at two levels: "IIf referring to practices developed by the cultural community:] Reactivating or reinventing social practices and representations, which are no longer in use or falling in disuse. [If referring to heritage policies:] The encouragement and support of a local community, developed with the agreement of that same community, in the reactivation of social practices and representations, which are no longer in use or falling in disuse." This fundamental difference presupposed, therefore, the active participation of local social agents in the decision to continue their practices or not, respecting in full their right to decide whether and how to do so.

\section{'Safeguarding' in the 2003 Convention: thematic axes}

Over the course of drafting and maturing the text of the Convention, we can observe the concern to define its own object and the form of safeguarding appropriate to it, diverging from other Conventions with which it implicitly dialogued and from which it sought to distance itself, as in the case of the 1972 Convention. 
The need to recognise the specificities of the different modes of safeguarding appropriate to objects of an intangible nature conferred the concept of 'safeguarding' - as we shall see below - a meaning quite distinct from that attributed to the concept of 'preservation,' widely adopted in the heritage field. It should be observed, however, that, in practice, 'safeguarding' ended up becoming an umbrella term covering a semantic field where 'preservation,' 'conservation' and 'protection' designate degrees and modes of intervention in different aspects of this object within which each State Party, each local manager, each consultant and even each cultural community make their choices when developing concrete safeguarding actions.

From the viewpoint of the theme focused by these Comments, the final version of the Convention meets most of the innovative theses resulting from the meetings of specialists organised by UNESCO, the most important and more problematic of them, in strategic terms, being the one referring to the role of the agents of cultural communities in the safeguarding process. On this point, it is worth observing that the practical application of the Convention imposes changes to the understanding of key devices, as occurs with the theme which in the Preamble is presented as follows: "Recognizing that CGIs play an important role in the production, safeguarding, maintenance and recreation of ICH (...)." In the document Ethical Principles for Safeguarding $\mathrm{ICH},{ }^{22}$ issued in 2015 , the same theme appears as follows: "Communities, groups and, where applicable, individuals should have the primary role in safeguarding their own intangible cultural heritage." The critical point of this topic is the nature of the relation that the States Parties establish with the CGIs through their heritage agencies. However, this issue depends on the conditions in which, in each country, society participates in the public sphere, a question that goes beyond - far beyond - the limits of the provisions of a multilateral convention.

To present the theme of 'safeguarding' as conceived in the 2003 Convention in a summarized form, I shall use the resource of identifying axes at whose intersections I heuristically situate this notion. These axes show themselves to be relevant to understanding problems that emerge in the application of this heritage regime, which, due to a lack of space, cannot be discussed in these reflections.

I turn, then, to comment on each of these axes, adopting the framework announced at the start of these reflections, in which safeguarding is understood as a verb, ${ }^{23}$ that is, as an action implemented by determined agents, directed at specific target communities, aiming to affect particular aspects of the cultural dynamic of concrete social formations and to produce determined effects on this dynamic.

1. Intangible elements. ICH elements are practices and knowledge associated with these practices, not artefacts. Tangible objects can participate in the universe of realities to be safeguarded - through identification, documentation, research, preservation and protection - as preconditions for realizing these practices and implementing this knowledge, i.e. merely instrumentally, as occurs with language, which is included only as a vehicle of the ICH (Article 2.1; Article 2.3; Article 14.c).

2. Nurturing mutable actions, not collecting documents. The main objective of safeguarding is not to produce and collect ethnographic records per se, as ethnographic archives and museums have done for more than a century. ICHs are not frozen in time. They transform in the same way as the social practices transform that provide their context, nourish them and give them a raison d'être, making their continuity viable, or non-viable. Changes and the abandonment of social practices are commonplace in the history of humanity and it would be impossible to argue for a cultural policy that sought to preserve some practice without the active adhesion of the social groups that practice them, develop them, know how to enrich and transform them creatively. The understanding expressed in Article 2.1 concerning transformation as an inherent aspect of the ICH contrasts with the structuring conceptions of other heritage regimes, as in the case of the regime governed by the 1972

22 Approved at the 1oth Intergovernmental Committee Meeting in 2015.

23 Inspired by D. Harvey (2001). 
Convention. The fundamental point to consider here is that the vitality of intangible cultural heritage is associated with its resilience, that is, precisely with the capacity of the CGIs to "constantly recreate" [ICH] "in response to their environment, their interaction with nature and their history" in a way that provides CGIs "with a sense of identity and continuity, thus promoting respect for cultural diversity and human creativity" as affirmed by Article 1.1. To be effective, safeguarding must respond to this condition of resilience.

3. Human beings: tangible roots of the intangible. Given the immaterial nature of $\mathrm{ICH}$, through what means can a 'safeguarding' action attain its objectives? One reply to this question, which may appear odd, is to admit that ICH is a reality anchored primarily in people - not in territories, but in bodies and ways of life, in human beings. Here it is a question of embodied knowledge and forms of expression, whose development and transmission frequently depend on learning skills and knowledge expressed in gestures and movements, that is, bodily actions. Safeguarding thus becomes inseparable from the decision of the CGIs to actively pursue their practices and include them in their aspirations and future projects. As a result, they have a central role in safeguarding their heritage, which confers full meaning to the provisions of Article 11.b and Article 15.

4. Flexible territoriality. Unlike the built and natural heritage whose spatial localization is recognisable and whose continuity in the same space, given that they are immobile assets, is predictable, the object of this regime, as well as being dynamic and mutable, is mobile. Although ICH requires socioenvironmental conditions and resources for its realization and frequently expresses territoriality and a sense of place, it does not necessarily have ties 'of origin' with the geographic space where it occurs. Many elements of directly observable ICH derive from repertoires developed by communities different from their current exponents, located in other places and times, although in their current amalgamation they encounter their raison d'être and the meanings of identity attributed to them. Hence ICH elements can also be practiced today by migrant communities and dislocated populations living outside their territories of origin. In each case, the territory, socioenvironmental conditions and artefacts have different levels of impact on the safeguarding conditions, i.e. on the reproducibility of ICH. Hence ICH can be understood as practical and symbolic resources that move about with the populations, transported by practitioners or transmitted by the means of communication, and which, therefore, can flourish and bear fruit in new sites, distant from the locations from which they originate. There are indissociable, therefore, from the CGIs that practice them. (Article 2.1)

5. Universality, singularity. Due to the necessarily universalizing status of this multilateral agreement, it generates an immediate tension with the singular social formations from which its object emerges. The tension between the singularity of the practices and the universality of the devices contains an important underlying issue with at least two dimensions: while, on one hand, the Convention establishes the heritage value recognised by the practitioners as a primordial criterion for the selection of the object to be safeguarded, on the other it defines the inventory as an obligatory procedure (Article 11; Article 12) in its identification, just as in the heritage regimes relating to movable and immovable property whose nature is indeed more suitable to this procedure. ${ }^{24}$ Furthermore, the Convention proposes to contribute to the viability of a determined cultural element, yet it can only do so as an outside agent, a provider of resources that the community itself will never be sure to be able to control. Hence, it is essential to note that, despite all the emphasis and effort towards adopting a participatory paradigm in the implementation of this heritage regime, it derives from the logic and cosmology of the preservationist tradition, and not from the view of the world and the self of the social agents to whom the ICH is connected. It is highly unlikely that any community will spontaneously conduct systematic surveys and (methodo)logical selections of its own cultural practices. This tension between the logic of safeguarding and the logic of cultural reproduction, or between the power relations present in the two

24 Debates on the adaptation of inventories as identification procedures for ICH elements. 
cases, leads to innumerable problems relating to the efficacy of safeguarding, a topic that cannot be ignored in these Comments and which has been explored in a number of enlightening case studies (Foster \& Gilman 2015; Bendix et al. 2013; Adell et al. 2015).

6. Social value, not exceptionality. The regime established by the 2003 Convention, unlike others in force, rejects the notion of 'exceptionality.' The social value of the ICH for the communities involved, recognized by the States Parties and by those who participate in its relational universes, is one of the preconditions for the acceptance of its candidacy as the object of 'safeguarding.' However, these elements tend to have, by themselves, greater visibility than other components of cultural repertoires in their own contexts of origin. Moreover, they are frequently highlighted by the local media and disseminated through academic studies produced prior to their safeguarding, or stimulated by it. The seal of official safeguarding is frequently appropriated by the culture and entertainment market to its own benefit, very often with the consent and active participation of CGIs, in the expectation of receiving some of the benefits deriving from these enterprises. These factors need to be mentioned since they all contribute to an effect of exceptionality being produced, directly or indirectly, by safeguarding. A desire for visibility for the cultural element in question, or even for the CGIs through it, may be a motive that precedes their proposal for inscription in one of the Convention's Lists, but it will probably be an outcome stimulated and fed by the safeguarding process, whose collateral effects need to be mitigated by responsible heritage management (Arantes 2017).

7. Modalities of safeguarding. The safeguarding actions specified by the Convention can aim to revitalize a cultural element that finds itself in need of urgent (or extremely urgent) safeguarding and that can be included in the USL or, in the case of those included in the RL, directed more appropriately to the other actions specified in Article 2.3. Although an explicit definition of 'revitalisation' is absent from the Convention and the ODs, for the purposes of these Comments I shall make use of the understanding expressed in the Glossary cited previously and the contents of $\mathrm{ODU}_{3}$, which refers to "safeguarding measures that may enable the CGIs to continue the practice and transmission of the element." Although revitalisation is an exclusionary measure in relation to the others citied in Article 2.3, it is important to distinguish it by considering the effects of safeguarding on the vulnerability of each situation to which it is applied. For common sense reasons, projects that aim to promote and enhance ICH should not precede the overcoming of situations in which, in the terms of ODU2 (a), "the element is in urgent need of safeguarding because its viability is at risk despite the efforts of the CGIs and of the State Party concerned," or ODU2(b), "the element is in extremely urgent need of safeguarding because it is facing grave threats as a result of which it cannot be expected to survive without immediate safeguarding."

Returning to the question of the participation of CGIs in safeguarding, mentioned earlier, we should take into account that the ICH Convention is based on the principle of the "widest possible participation and involvement of CGIs" (Article 15) in all actions aimed towards the general objective of "ensuring the viability of the intangible cultural heritage." The provision should immediately be added that "to ensure the viability of the ICH" is a mission that goes beyond anything that any manager can achieve. In any event, the practical application of the principle of the widest possible participation slips up on the unequal distribution of wealth, power and access to the knowledge associated with these inequalities, which so strongly mark the historical reality in which we live, ourselves and the heritage communities. Furthermore, safeguarding also enters into friction with the marked differences in worldview - if not in ontologies (Henare et al. 2007), as has been posited more recently - between the diverse cultures in confrontation. And being, as I argued earlier, a work of metacultural construction through which a key cultural element migrates, so to speak, from the initial context of occurrence to those of UNESCO's Lists, it is to be expected that the diverse safeguarding measures encounter resistance, provoke misunderstandings and political difficulties, as has been shown by some recent studies, as pointed out above in item 5 . 
Abstractly, we can anticipate the following situations that illustrate the complexity and diversity of problems arising from the implementation of the safeguarding measures advocated by the Convention. The identification of an element of the ICH depends almost entirely on the CGIs for a question of principle, as specified in Article 2.1, and this 'almost' here is important given that a community would be unlikely to delimit motu proprio an element of its culture in the way expected by the Convention and without the input of the conceptual schemas brought by so-called facilitating agents. The activities of research and documentation, as well as promotion and enhancement, for their part, are based on knowledge and on technical and ethical norms that are defined, in the former case, in the academic environment, and in the latter case, in design and communication. Needless to say, these forms of knowledge and skills tend to be largely unknown by most of the CGIs, despite the existence of training activities for indigenous researchers, photographers, filmmakers and cultural agents, generally promoted by NGOs. Preservation and protection, in turn, are practices based on legal systems, administrative regulations and technical procedures that foreground heritage management agencies and agents with whom the CGIs have little or no contact, or in relation to whom they lack the intellectual and technical repertoires that would enable direct dialogues and negotiations to be initiated. For precisely this reason, civil society organisations enter at this point as mediators and heritage policy agents as facilitators. Finally, revitalization and transmission. These activities involve almost exclusively local agents since they depend on the status occupied by the agents transmitting the tradition within the local social structure, their legitimate access to the sources of knowledge, as well as the capacity and authority to create and recreate the ICH element according to the dictates of the language, values and worldview of the universe to which they belong. In this context, it is important to differentiate between 'transmission' and 'dissemination.' The former is an activity that results in the creative reproduction of social reality, a matter internal to the group, while the latter is a synonym of promotion, an activity that can be secondarily executed by anyone as long as they have the free, prior and informed consent of ICGs.

8. Mediation, negotiation. The heritage regime inaugurated by the 2003 Convention (Article 11.b; Article 15) creates a political space of negotiation - not necessarily of dialogue and participation - between the managers of the Convention and the CGIs. This is the strategic space in which 'safeguarding' may or may not take place. In pragmatic terms, the proposal is for the IGCs to negotiate with the public agents to identify those elements that they recognize as possessing a heritage value and that can be safeguarded. Their effective inclusion in the safeguarding actions is dependent on intellectual, legal, political and practical filters established by the process of inclusion or exclusion, acceptance or rejection of these candidatures on the lists created by the Convention, which will define the status and prerogatives of each of them vis-à-vis the diverse safeguarding instruments adopted. Following a favourable decision to include a cultural element on one of the Lists or international aid projects, a new stage is inaugurated in the trajectory of the selected practice, in which the State Party and the Organs of the Convention will subsequently monitor its evolution over subsequent years through regular assessment reports to be presented by the State Party involved. As I pointed out earlier, the UNESCO/ICH regime does not emerge from the experience of the heritage communities. With the aim of achieving the best possible outcome for the safeguarding process, therefore, the Convention proposes (Article 14.2) specific educational and training programs, as well as the accreditation of NGOs whose prior knowledge of the CGIs and political relations previously established with them can be elements facilitating the adequate participation of the CGIs in safeguarding. This comprises a tight-knit space, constructed by complex webs of mediators, in which the CGIs correspond to the furthest extremity of the Organs of the Convention. 


\section{Final considerations}

I conclude these Comments by once again calling attention to recent studies that have demonstrated the complexity of the processes through which the procedures advocated by the Convention have become a reality. In order for safeguarding to be effective, it is essential to create mechanisms of communication and participation that open up channels between the diverse cultural and power spheres that its actions need to transpose. In part, this is a task relating to the normative provisions of this regime, inscribed in the text of the Convention and in the Operational Directives, which comprise a flexible instrument more permeable to the reflexive effects of safeguarding and can always be improved.

But this alone is not enough. It is also necessary for the parties in confrontation to know each other, as far as this is possible. It is not difficult to imagine - and those readers familiar with the practice of this regime will certainly recognize this fact clearly - that the cultural distances to be spanned by the safeguarding agents are diverse, broad and complex, and that sometimes the strength of the political obstacles to be overcome is immense. Here I am not referring solely to the resistance of the CGIs, but mainly to the ideological and party-political barriers imposed subtly or openly by the States Parties, which moreover vary according to the political conjunctures of each country at any particular moment.

It therefore becomes a primordial task of those who implement this instrument to direct their energies towards ensuring that the complex system of mediations and negotiations created by this regime recognizes the conceptions, demands and aspirations of the CGIs and becomes responsive to them. Safeguarding involves the development of a two-way process. Considering the question from an ethical standpoint, it is more defensible that the managers promote the adaptation of the Convention's objectives and instruments to the realities found locally, with all their variations, rather than act like international politics and try to reconfigure - or at least reformat for the purposes of dossier production - enrooted cultural practices with a high value for awareness of the self and the other.

In fact, when it comes to ethics, in order for mutual understanding and partnership to exist among the safeguarding agents, the action must be based on shared principles and not simply excused by the questionable free, prior and informed consent of its recipients or target public. ${ }^{25}$

Translated by David Rodgers

Received: January 31, 2019

Approved: February 19, 2019

25 Work in this direction was undertaken by the IGC which approved the 'Ethical principles for safeguarding intangible cultural heritage,' which establishes, at the outset, that "CGIs should have the primary role in safeguarding their own ICH." 


\section{References}

ADELL, Nicolas; BENDIX, Regina; BORTOLOTTO, Chiara; TAUSCHEK, Markus (eds.). 2015. Between imagined communities and communities of practice. Göttingen Studies in Cultural Property, vol. 8. Göttingen: Göttingen University Press.

ARANTES, Antonio. 2017. "Transformative impacts of the ICH Convention. Notes for discussion" In: Tomiyuki Uesugi; Mari Shiba (eds.). Glocal perspectives on intangible cultural heritage: local communities, researchers, states and UNESCO, with special focus on global and national perspectives. Tokyo: Centre for Glocal Studies, Seijo University. pp. 19-30. . 2019. "'Safeguarding', a key dispositif of the ICH Convention". Vibrant (in this issue).

BENDIX, Regina; EGGERT, Aditya; PESELMANN, Arnika (eds.). 2013. Heritage regimes and the State. Göttingen Studies in Cultural Property, vol. 6. Göttingen: Göttingen University Press.

FOSTER, Michael Dylan; GILMAN, Lisa (eds.) 2015. UNESCO on the ground. Explorations in folklore and ethnomusicology. A Journal of Folklore Research Book. Bloomington: Indiana University Press.

HARVEY, David. 2001. "Heritage pasts and heritage presents: temporality, meaning and the scope of heritage studies". International Journal of Heritage Studies, 7(4): 319-338.

HENARE, Amiria; HOLBRAAD, Marin; WASTELL, Sari (eds.) 2007. Thinking through things. Theorising artefacts ethnographically. Routledge: London.

IKAWA-FAURE, Noriko. 2009. "From the Proclamation of Masterpieces to the Convention for the Safeguarding of Intangible Cultural Heritage”. In: Laurajane Smith; Natsuko Akagawa (eds.) Intangible heritage. Routledge: London. pp. 13-44.

JAKOBSON, Roman. 1963. "Linguistique et poétique”. Essais de linguistique générale. $2^{\text {nd }}$ edition. Paris: Les Éditions de Minuit. pp. 217-218.

KIRCHENBLATT-GINBLETT, Barbara. 2004. "Intangible Heritage as Metacultural Production”. Museum International, 56(1-2): 52-65.

KONO, Toshiyuki (ed). 2009. Intangible heritage and intellectual property. Antwerp: Intersentia.

\section{Antonio Arantes}

State University of Campinas, Department of Anthropology, Campinas/SP, Brazil

Author's email: arantes1@unicamp.br

http://orcid.org/0000-0002-2463-680x 


\title{
Annex
}

\section{International Meeting of Experts on Intangible Cultural Heritage}

\author{
ESTABLISHMENT OF A GLOSSARY
}

UNESCO Headquarters, Paris, 10-12 June 2002

\section{Report}

\section{Session 1: June 10, morning}

\author{
Agenda item 1. Opening Remarks
}

Mr. Mounir Bouchenaki, Assistant-Director General for Culture of UNESCO, opened the meeting. He recalled the purpose of the occasion, which is to bring elements of clarification to the expression "intangible cultural heritage" and to various notions related to it. He mentioned that the protection of this heritage has been the subject of several experts' meetings and documents, such as the 1989 Recommendation on the Safeguarding of Traditional and Popular Culture and the 1999 World Evaluation of the 1989 Recommendation. He stressed that during a meeting held in Turin (March 2001) an agreement was made on an operational and synthetic definition of that expression and that an indicative list of related terms has been outlined. He also recalled that in the Rio de Janeiro meeting (January 2002) experts recommended the preparation of a glossary in order to clarify the drawing up process of the future convention. Finally, he noted that during the meeting of the Restricted Drafting Group held in March 2002, the experts suggested that the terminology adopted for the convention should be more specific than the one used in the Turin meeting, and that an indicative list of domains of intangible cultural heritage should be elaborated. He concluded by urging the experts to establish such a list of basic concepts and domains. He proposed that the meeting should be held under the presidency of $\mathrm{H}$. E. Judge Mohamed Bedjaoui, the vice-presidency of Mr. Sompong Sucharitkul and Mr. Wim van Zanten and reported by Mr. Antonio Arantes.

H.E Bedjaoui welcomed the participants. Presenting the domain of intangible cultural heritage as a new field of concern for UNESCO, he outlined the aims of the meeting stressing the following aspects: i) the necessity, underlined in the Rio de Janeiro meeting, to elaborate a glossary of useful terms and notions for the drafting of the new convention, ii) the necessity to bear in mind the critical remarks made during the last session of the Executive Board in the sense that although the definition of intangible cultural heritage retained during the Turin meeting is perfectly valid from a scientific point of view, it is too abstract for operational application. For the same reason, domains should be listed and the experts should elaborate elements of conceptual clarification. He emphasised that the glossary should be considered as a working tool, and not as part of the future convention. 


\section{Agenda item 2: Presentation of the document TER/CH/202/WD4: Draft Glossary, by the experts convened by the bureau of the Netherlands National Commission for UNESCO.}

Mr. Rieks Smeets, the Secretary General of the Dutch Commission, welcomed the participants and introduced the set of draft definitions of terms to be used in the Convention as prepared by the Dutch group of experts in response to a request made by UNESCO's Secretariat. He underlined that this group of experts took into consideration the critical remarks made by the Executive Board in its last session.

\section{Agenda items 3 and 4: The definition of intangible cultural heritage and its constitutive domains.}

The following text, elaborated by the Dutch commission, was provided as a first draft of the definition: "Intangible cultural heritage: all processes and practices - together with the knowledge and skills, instruments, artefacts, and spaces involved - that provide living communities with a sense of continuity with previous generations and are important to cultural identity, as well as to the safeguarding of cultural diversity and creativity of humanity. Communities and individuals in the contemporary world continue to recreate their intangible cultural heritage in constant response to their environment and to historical conditions. The intangible cultural heritage consists of such human creations of the mind that are recognised as having significance for a social group and which represents exceptional attainment of human talent. These may be listed - without a claim to exhaustiveness - as below: oral expressions; performing arts; social practices, rituals and festive events; knowledge and practices about nature."

Opening the discussion, Ms. Lourdes Arizpe gave an overview of the context in which the definition of intangible cultural heritage was formulated in the Turin meeting. She noted that it had to compress a centurylong debate in the social sciences about the concept of culture, as well as important political changes that took place in the world in the last decades. Four main issues were discussed in Turin: i) in order to adequately account for the present situation of intangible heritage, emphasis should be put on cultural processes, on the culture-bearing communities and in local agency; ii) the safeguarding of cultural diversity should account for the conditions that create and recreate it in time, as well as provide the means for the communities to enjoy these cultural/social differences; iii) modes of social interaction as well as artistic products should be taken into account; iv) the importance of human, political and religious tolerance for the present world should be stressed. She asked Mr. Antonio Arantes to inform the audience about the Brazilian legislation and on the outcome of the international meeting of experts held in Rio de Janeiro.

Mr. Antonio Arantes observed that in the Rio de Janeiro meeting the concern for intangible heritage in modern cultures was in line with the critique of the nostalgic and romantic understanding of such realities and with the assumption that culture is constantly produced, reproduced and transformed. He gave examples from Brazil and added that one should be flexible with the notions of "tradition" and "autochthony" while drafting the future convention. He argued that the experts' meeting therefore supported the view expressed in Turin that in the definition of the parameters for this new policy, the main emphasis should be put in the understanding of heritage as the result of dynamic social practices in particular historical contexts and natural environments.

He summarised the legislation and provided an overview of the four domains that constitute the Brazilian Registry, namely: Knowledge [including traditional crafts], Celebrations [rituals and festive events], Ways of Expression [except natural languages] and Places. The definition of these items, he noted, was oriented by the understanding that intangible heritage are constitutive of social practices and that, consequently, its identification should be based on the following aspects of social life: agency, people and process. Intangible heritage, he concluded, are resources that people develop and use in everyday life; so to his view it is fundamental that safeguarding policies be implemented with a view to develop the social and economic potentialities of these resources for the well-being of their bearers. 
Finally, he listed the main outcomes of the Rio meeting, namely: the agreement with the main aspects of the definitions elaborated in Turin; the need of flexibility in the definitions adopted by the convention, given the heterogeneity of the national and regional contexts to which they will be applied; the recognition of the right to difference and to cultural diversity as a baseline for this new policy; the importance of intangible heritage for sustainable development; the emphasis on people and processes; the use of internal and external criteria in the selection of items to be listed as heritage; the need for a holistic approach interrelating intangible heritage with the natural resources and with the material objects that are needed for its existence.

In the discussions that followed, several participants made reference to two interrelated issues: i) the safeguarding of the material and social conditions in which intangible cultural heritage is produced, ii) the recognition of the creative ability of the people and of the constant transformation of such heritage.

Several experts manifested their preoccupation about the issue of who has the authority to define intangible cultural heritage. Should the responsible authority be the bearers of the local culture, or rather professional experts or state agencies? The dominant opinion was that such authority should ultimately rest on the local people itself. The ability of people to recreate or reinvent their own traditions for the purpose of social cohesion was again stressed. It was strongly argued that in this policy balance should be achieved between what the external agencies consider worth of becoming part of the internationally safeguarded heritage and the choices made by the communities themselves.

The debate then focused the list of domains proposed in the Dutch draft document. Besides suggestions concerning the terminology in use (e.g., to replace "oral expressions" by "oral traditions"), the inclusion of "arts and crafts" as one of the domains of intangible heritage was suggested. Against such view, it was argued that handicrafts often fall under the category of market-oriented commodities.

It was also proposed that the idea of intangible cultural heritage as social representation should be retained by the Convention. Thus, it was suggested that the expression "collective creations" should be replaced by "individual creations that are adopted as representation by communities". Another participant argued that individuals work and create within groups and that reference to the term "individual" should be therefore avoided.

The need of establishing a close link between "tangible" and "intangible" aspects of heritage was also addressed. Some participants expressed their concern for the protection of tangible aspects of intangible culture. Participants acknowledged the view that at one point, creative processes develop into material objects. It was recalled that in both common law and in Roman law, such a link is admitted and conceptualised. The Secretariat, in its turn, underlined that the protection of many aspects of material culture was already covered in the 1970 Convention on illicit traffic and in the 1955 UNIDROIT Convention. It was also argued that the process of producing artefacts, as well as the meanings associated to them, are more relevant to intangible heritage than the material objects themselves.

It was observed that WIPO mainly deals with the protection of recent and individual creations, but not with objects created by groups "from times immemorial". Thus, the inclusion of the term "artefact" in the domains covered by the convention was suggested. The Dutch commissioner recalled that the term "artefacts" had been originally included in the list. Another participant noted that it was urgent that the policy concentrates on the specifically intangible aspects of heritage, since they have been quite neglected, especially in Europe.

The question of who should have the authority to decide about the safeguarding of intangible cultural heritage was again addressed. In order to clarify the matter, Ms. Sue Wright pondered that there are two possible procedures. One is the elaboration of a registry inspired by the UNESCO program "Memory of the World" (paragraph 4, item 4.3.3 and 4.3.4), were the nominating process can be taken over by "any person"; the other is listing, a procedure that raises the issue of weather the selection should rely on criteria such as quality, uniqueness, exceptionality, or, alternatively, risk. Each has different implications from the point of view of the subject under discussion. 


\section{Session 2: June 10, afternoon.}

\section{Agenda items 3 and 4: Definition of intangible cultural heritage and its constitutive domains. (continued)}

The session was opened by the Vice-president Mr. Wim Van Zanten, with the proposal of discussing in detail the domains to be enumerated in the Convention, taking as a reference the text elaborated by the Dutch commission.

There were several proposals indicating that social practices and forms of social organisation created by the communities (such as systems of kinship and marriage), as well as rites, celebrations and other social practices, should be considered as heritage. In this context, the distinction between everyday culture and the exceptional manifestations of human creativity was discussed. The dominant opinion was that the inclusion of social practices as a domain of intangible cultural heritage would make the definition excessively vague and, consequently, not very useful.

The relation of intangible cultural heritage with social continuity and identity was then discussed and the general feeling was that conceptions about social life based on ideas of consensus and homogeneity should be avoided. They do not account for the reality of dynamics and change that take place in history.

The theme of the tangible side of intangible heritage was again addressed, with reference to the fact that the word "product" (used in the Turin definition), was missing in the draft under discussion. A long discussion followed in relation to the concepts of "artefact" and "object", the first one being considered as more adequate for the presente context because of specifically refering to products of human practices. Finally, both terms were adopted because each describes a different aspect that is crucial for intangible heritage: man made and natural resources.

The Vice-President made a summary of the results achieved by the experts up to that stage of the meeting. The discussion then focused the use of the notion of "exceptionality" in this context. Although some participants stressed that the definition of intangible heritage should include a wide range of social practices, the dominant idea was that heritage - particularly as object of the Convention - could not be identical to "daily life".

The Secretariat of UNESCO pointed out that, if there is a list, the second part of the definition should indicate the domains covered by such heritage, as it is the case in the 1972 Convention. The necessity of having explicit criteria was put as fundamental.

It was then stressed that it had already been agreed by this assembly, as well as in the previous meetings (Rio de Janeiro and Turin), that one criterion for selection should be the relevance of the cultural item to the communities themselves. Besides this, heritage should also be significant to humanity and consistent with human rights. It was pointed out that the use of the idea of "exceptionality" could also induce the misleading and unacceptable principle that some cultures are better or richer than others. Alternative criteria such as "distinctive" or "outstanding" were then proposed as a way of avoiding this bias in the elaboration of lists. One participant proposed to include the phrase "contribute to the creativity of humanity" as figured in the Turin definition.

The next question under discussion was that the definition should start with a broad characterisation of its object and that another provision should state the conditions under which it will be safeguarded. This was the perspective adopted by the assembly.

The President proposed that the rapporteur prepare a report of the meeting and that the definition be proposed for final discussion in the morning session of Wednesday 12 June. 


\section{Session 3: June 11, morning.}

\section{Agenda items 3 and 4: Definition of intangible cultural heritage and its constitutive domains. (Continued)}

The vice-president opened the debates taking as reference the following text produced by the Rapporteur, as a consolidation of the results of the debate so far: "Intangible cultural heritage consists of all processes and practices - together with the knowledge, skills, instruments, objects, artefacts and spaces involved - that provide living communities with a sense of continuity with previous generations. These processes and practices are relevant to the cultural identity of the people concerned as well as to cultural diversity, and contribute to the creativity of humankind. Communities and individuals in the contemporary world decide how to recognise their intangible cultural heritage and continue to recreate it in constant response to their environment and historical conditions of existence. As an object of the present convention, and within the limits set by the Declaration of Human Rights, intangible cultural heritage is constituted by the distinctive and outstanding achievements of human creativity. These may be listed - without a claim to exhaustiveness - as below: 1. Oral expressions. 2. Performing arts. 3. Social practices, rituals and festive events. 4. Knowledge and practice about nature".

Two main issues were raised in the discussion. On the one hand, whether or not an explicit reference should be made to "human rights" and to "distinctiveness" as a criterion to be used in the proclamation of intangible heritage. On the other hand, how to articulate a general definition of intangible heritage as such, regardless of policies developed by UNESCO, with the necessity to set limits to its application with the context of the Convention. In the context of those limits, the inclusion of principles such as "respect for other cultures" and "observation of the human rights" as part of these limiting criteria was again addressed.

Concerning the question of human rights, it was argued that the idea of "respect for human rights" should not be included in a theoretical definition of intangible heritage as such and that a specific clause should state that no item would be enforced by the Convention if it violates those rights. It was also noted that the phrase "safeguarding of cultural diversity and creativity of humankind" included in the definition already addressed this issue and precluded the inclusion of any kind of harmful cultural practice in a future heritage list. Others argued that reference to human rights should be made in the general definition in order to make it clearly consistent with the discourse and ideals promoted by UNESCO. It was consensual that the Convention should clearly state that this policy should not contemplate practices that were harmful to other cultures.

Various proposals were made concerning the inclusion of an explicit reference to human rights and to the question of distinctiveness in the Convention. It was also suggested that this topic could use the wording of article 12 in the Turin action plan (i.e., "must be founded on universally accepted human rights, equity and sustainability and on respect for all cultures that also have respect for other cultures"). It was finally decided that the article stating the definition of intangible cultural heritage should be written in three levels, each concerned with a specific aspect of the matter: the general definition, the list of domains, and the criteria to be adopted by the policies derived from the Convention.

Several changes and amendments were proposed. The following text consolidates the dominant views so far: " 2 (a) Intangible cultural heritage means the processes and practices - together with the knowledge, skills, instruments, objects, artefacts and spaces involved - that provide living communities with a sense of continuity with previous generations and are constitutive of their cultural identity. It contributes to cultural diversity and to the creativity of humankind. Communities and individuals in the contemporary world decide how to recognise their intangible cultural heritage and continue to recreate it in constant response to their environment and historical conditions of existence. $2(b)$ these processes and practices may be listed -without a claim to exhaustiveness - as below: 1.Oral expressions. 2. Performing arts. 3. Social practices, rituals and festive events. 4. Knowledge and practice about nature. 2 (c) The safeguarding of intangible cultural heritage must be founded on universally accepted human rights, equity and sustainability and on respect for all cultures that also have respect for other cultures" 


\section{Sessions 4, 5 and 6: June 11, afternoon through June 12, afternoon.}

\section{Agenda items 2 and 5: Elaboration of a glossary}

The vice-president opened the debates about the glossary draft prepared by the Dutch commission, which includes thirty-five prelisted categories. (Document TER/CH/2O2/WD4: Draft Glossary). The discussion and reformulation of these concepts, as well as the inclusion of new categories and the refinement of intangible cultural heritage definition were the issues focused by the experts until the end of the meeting, in the afternoon session of June 12.

Four new categories were included as a consequence of the discussions held on the previous sessions of this meeting: 1) Living (contemporary) community. 2) Social practice. 3) Culture. 4) Knowledge and practices about nature. Other nine were added by the plenary: 1) Performing arts. 2) Festive events. 3) Place. 4) Sustainability.5) Agency. 6) Representation. 7) Creativity. 8) Documentation. 9) Researchers, administrators and managers.

From the total of forty-eight categories under scrutiny, thirty-eight were discussed exhaustively in these three sessions. Sixteen items were suppressed from the glossary draft either because it was of general agreement that they were not relevant for the Convention, or because no specific connotation was added by the present context of use to their current meaning. These were: 1) Indigenous. 2) Indigenous people.3) Local population. 4) Social group. 5) Ethnic group. 6) Actor. 7) Indigenous knowledge. 8) Traditional knowledge. 9) Living culture (community). 10) Folklore. 11) Mixed (hybrid) culture. 12) Tradition. 13) Traditional. 14) Product. 15) Knowledge and practices about nature. 16) Ritual.

The plenary arrived to consensual definitions about the following twenty-two categories: 1) Community. 2) Cultural community. 3) Indigenous community. 4) Local community.5) Culture. 6) Traditional culture. 7) Popular culture. 8) Social practice. 9) Agency. 10) Process. 11) Representation. 12) Creativity. 13) Safeguarding. 14) Preservation. 15) Protection. 16) Conservation. 17) Documentation. 18) Bearer. 19) Practitioner. 20). Custodian. 21) Creator. 22) Researchers, administrator and managers.

The discussion of each term of the list was long, careful and dense. It took as a reference the draft prepared by the Dutch commission as well as texts elaborated by Mr. Paul Kuruk (safeguarding, preservation, protection, conservation) and by Mr. Oskar Elschek and Mr. R. Regenvanu (practitioners, custodians, creators, bearers, researchers, administrators, culture professionals). A summarised report about the discussions that took place during the meeting would not provide an accurate picture of the work done by the experts on this matter. As the whole session has been tape recorded, these live records can provide the needed background of the present text. Nevertheless, some aspects of that discussion should be highlighted here.

In the first place, the plenary was very attentively critical to any definitions that would contribute to a reification of the idea of intangible heritage or derived from an understanding of society as a homogeneous, undifferentiated and static context. Consequently, the definitions are coherent with the notions of practice, process and agency that today have a very widespread use in Anthropological research and have been emphasized by the experts' meetings that took place in Turin and in Rio de Janeiro.

Second, the use of the notion of folklore in this context was very extensively debated. Some argued, particularly Mr. Paul Kuruk, that in several contexts and predominantly in African countries, this category still has a positive connotation and covers important cognitive, religious and symbolic domains. However, this is not the case in many other parts of the world, such as the Americas, Europe and the Pacific, where it is often associated with entertainment industry or with evolutionistic and nostalgic views about the past and the so-called "primitive" societies. So, it was agreed that other categories and expressions should be preferred.

A third aspect to be highlighted is the discussion about the ideas of preservation, conservation and protection, as this has also raised a very long and rich debate. The question was: to what extent a terminology that has been consolidated through decades of application to material objects and built structures is applicable to 
intangible heritage? Some members of the assembly suggested that these notions could have their meanings adapted to the specific characteristics of this type of heritage. The UNESCO Secretariat, on its turn, emphasized that these notions are consecrated in the field of heritage, and that it is plausible to foresee that they will be broadly used also in relation to intangible heritage.

However, the vast majority of experts consistently argued that one distinctive characteristic of this type of heritage is its intrinsically dynamic nature, due to the fact that it is an integral part of the social organisation and history of the communities concerned. It was also consensual that the future policies should not only take into account, but also actively recognise, the right and capacity that cultural communities have in making their own choices as to whether or not give continuity to aspects of their own culture. So, it became clear that the word that most adequately and broadly describes the particular kind intervention that would be adequate to the nature of this heritage is safeguarding, and consequently that this should be chosen as the basic notion implied in this context. Consequently, the plenary endorsed the wording used by other commissions in the elaboration of the preliminary versions of the Convention. The types of action referred to in the definition of safeguarding (i.e. identification, documentation, promotion, revitalisation and transmission) are those that the experts felt adequate to this new policy and which are considered compatible with the definition produced by this meeting.

\section{Agenda item 7: Conclusion}

Since the time planned for this meeting was not enough for an exhaustive discussion of all the categories and issues raised by the experts, it was decided that the discussion about the ten following concepts, provisionally defined during the meeting, should continue by means of the Internet: 1) Revitalisation, 2) Promotion, 3) Transmission, 4) Oral expression, 5) Oral tradition, 6) Performing arts, 7) Festive event, 8) Cultural space, 9) Place, 10) Sustainability.

A complete and final version of the definitions produced by this group of experts is presented in the document entitled Draft Glossary on Intangible Heritage.

As a final topic, the plenary analysed and approved the following definition of intangible cultural heritage and its constitutive domains: (i) For the purposes of the present Convention, intangible cultural heritage means the practices and representations - together with their necessary knowledge, skills, instruments, objects, artefacts and places - that are recognised by communities and individuals as their intangible cultural heritage, and are consistent with universally accepted principles of human rights, equity, sustainability, and mutual respect between cultural communities. This intangible cultural heritage is constantly recreated by communities in response to their environment and historical conditions of existence, and provides them with a sense of continuity and identity, thus promoting cultural diversity and the creativity of humankind. (ii) Intangible cultural heritage, as defined in paragraph (i) above, covers the following domains: 1) Oral expressions, 2) Performing arts, 3) Social practices, rituals and festive events, and 4) Knowledge and practices about nature. 


\section{Closing session: June 12, afternoon.}

Mr. Mounir Bouchenaki, Assistant-Director General for Culture of UNESCO closed the meeting, thanking the experts for their relevant contribution to this important task, particularly mentioning the contributions of the Dutch commission for the preparation of the draft documents, of Mr. Wim Van Zenten who presided most sessions, and of Mr. Antonio A Arantes as rapporteur.

Meeting documents available at https:/ich.unesco.org/en/events?meeting_id=00o82

Glossary. Intangible Cultural Heritage. Prepared by an international meeting of experts at UNESCO, 10-12 June 2002. https:/|ich.unesco.org/doc/src/00265.pdf

\section{Errata}

In Volume 16, of Vibrant: Virtual Brazilian Anthropology, published in February 2019, in the section "Dossier Safeguarding, its Genealogy and Governance. Two Essays on UNESCO's Convention for the Safeguarding of Intangible Cultural Heritage", the article of Antonio Arantes with DOI http://dx.doi.org/10.159o/180943412019v16a2o1 had their titles changed.

In english:

For

The governance of safeguarding. Comments on Article 2.3 of the ICH Convention

Read

The Governance of Safeguarding. Comments on Article 2.3 of UNESCO's Convention for the Safeguarding of Intangible Cultural Heritage

In Portuguese:

For

Gestão da salvaguarda. Comentários ao Artigo 2.3 da Convenção do Patrimônio Cultural Intangível

Read

A Gestão da Salvaguarda. Comentários ao Artigo 2.3 da Convenção da UNESCO para a Salvaguarda do Patrimônio Cultural Intangível 